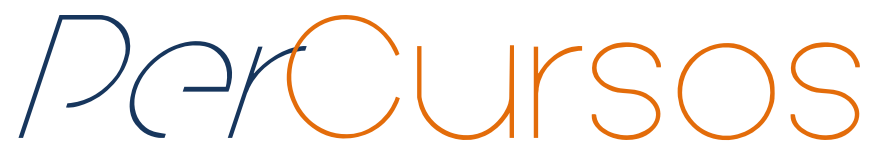

\title{
Filhos/as adotivos/as, quando revelar este segredo
}

\section{Resumo}

Este estudo teve como finalidade investigar os aspectos que geram ansiedade nos pais adotivos no momento da revelação da adoção e da história pré-adotiva ao filho. A base de relações saudáveis é mantida através do princípio da verdade. Assim, quando os pais omitem do filho a condição de ser adotado, e sua historia de origem, além de estarem prejudicando-o na construção de sua identidade, fazem com que a confiança entre ambos fique prejudicada. Participaram da pesquisa cinco famílias que fizeram acompanhamento no estágio de convivência de adoção, no Centro de Psicologia Aplicada da Universidade de Passo Fundo, as quais participam do Projeto de Extensão de Terapia Familiar com Famílias Adotivas. Cabe à Psicologia desconstruir preconceitos em relação à adoção, propiciando, tanto aos pais quanto aos filhos adotivos, uma melhor compreensão de que para se estabelecer uma relação saudável é necessário não haver segredos dentro do âmbito familiar.

Palavras-chave: Adoção. Pais e filhos adotivos. Revelação da adoção.

\author{
Elisiane Valandro \\ Formada em Psicologia pela \\ Universidade de \\ Passo Fundo - UPF \\ lisi.valandro@yahoo.com.br
}

\section{Silvana Terezinha Baumkarten}

Doutora e professora em

Psicologia pela Universidade de

Passo Fundo - UPF

silbpsico@gmail.com

\section{Para citar este artigo:}

VALANDRO, Elisiane; BAUMKARTEN, Silvana Terezinha. Filhos/as adotivos/as, quando revelar este segredo. Revista PerCursos. Florianópolis, v. 14, n.27, jul./dez. 2013. p. 56 - 86.

DOI: $10.5965 / 1984724614272013056$

http: //dx.doi.org/10.5965/1984724614272013056 


\title{
Adoptive children, when the secret must be revealed
}

\begin{abstract}
The aim of the study was to investigate the aspects that generate anxiety in adoptive parents, when the disclosure of adoption occurs, as well as the pre-adoptive history is told to the child. Considering the truth is the basis of healthy relationships, when parents omit the child's condition of being adopted and his/her origin history, they damage his/her identity construction process. Besides that, the trust relation between them becomes impaired. Five families who made up the coexistence adoption stage participated in the research at the Center for Applied Psychology, at Universidade de Passo Fundo; moreover they currently participate at the Extension Project 'Family Therapy with Adoptive Families'. Psychology has a compromise to deconstruct prejudices regarding to adoption, providing both adopted parents and their children a better understanding that there must be no secrets within the family to establish a healthy relationship.
\end{abstract}

Keywords: Adoption. Adoptive parents and children. Disclosure of adoption. 


\section{Introdução}

A revelação da adoção e das origens da criança é marcada por muita angústia e fantasia, tanto por parte dos pais quanto por parte dos filhos, razão pela qual esse momento pode trazer muitos conflitos e desentendimentos. Muitos pais não se opõem à discussão da adoção abertamente, mas confessam que a evitam, explica Ladvocat (2002). Por se tratar de assunto que gera muita ansiedade quando surge, não há estímulo ao diálogo, e os pais tendem a evitar a responder perguntas sobre as origens do filho, o que acaba gerando mitos sobre a adoção, tanto nos adotantes quanto nos adotados, e provocando um espaço vazio na comunicação de ambos.

Segundo Ladvocat (2002), os pais adotivos preferem muitas vezes omitir as informações que eles possam ter sobre as origens de seus filhos, ou ainda optam por não conhecer essas origens, devido ao medo de entrar em contato com algo temido, demonstrando, assim, suas crenças sobre as influências da hereditariedade na vida da pessoa adotada. Os pais acreditam que se a criança foi abandonada ou entregue à adoção, pode ser fruto de hereditariedade suspeita, resultado de prostituição materna, drogadição, criminalidade ou problemas de conduta por parte dos genitores, fatores que podem gerar identificações insuportáveis e, diante desses aspectos temidos, terminam por "justificar" a necessidade do segredo sobre a origem da adoção para os seus filhos (LADVOCAT, 2002).

Nesse sentido, este artigo busca trazer informações que ajudem a compreender as famílias adotivas nesse momento vivenciado com uma intensa carga emocional diante da revelação da adoção e da sua historia pré-adotiva, bem como busca identificar quais sentimentos pais e filhos sentem no momento da revelação de tal segredo.

Dolto (apud LIPP. MELLO; RIBEIRO, 2011) traz algumas contribuições na compreensão da adoção, afirmando que não há uma idade específica para a revelação de uma adoção. Aliás, ressalta que esta jamais deve ser escondida, mesmo que a criança ainda não entenda bem o significado da palavra. O autor prossegue afirmando que a adoção deve ser anunciada e contada à criança e às pessoas que fazem parte do círculo de relações desses pais de maneira natural e verdadeira. A todo sujeito é necessário o conhecimento de sua história, a respeito do que Sanches (apud LIPP; MELLO; RIBEIRO, 
2011) desenvolve uma metáfora: "assim como as raízes de uma árvore sustentam sua estrutura, é essa história que possibilita à criança sentir-se como um ser que pertence a algo maior e que vai dar sentido às experiências que têm". Salienta Ladvocat (2002) que se os filhos perceberem nas suas famílias a dificuldade em dialogar sobre suas origens, eles fantasiam sobre o tema, criando seus próprios mitos e preconceitos. Então, se tanto a origem quanto a efetiva adoção permanecem ocultas, a criança pode supor que, por alguma razão, esses pontos devem ser escondidos e guardados, surgindo então um claro sentimento de vergonha e de preconceito também quanto ao status de ser adotada. De acordo com Sanches (apud LIPP; MELLO; RIBEIRO, 2011), a dificuldade de revelar a adoção é uma questão dos adultos que, uma vez atravessados pelo discurso social, defendem a ideia de que como a criança já sofreu muito com o abandono da mãe biológica, é permitido, então, aos pais, omitir a adoção e silenciar-se frente a essa difícil história, como se, com isso, pudessem poupá-la do sofrimento. Quando a adoção é abordada como algo natural, aberta a questões sobre sua origem, é a base para o relacionamento saudável entre pais e filhos; mas quando tratada em forma de segredo, pode ocasionar problemas, por ser vista como assunto proibido e repleto de crenças e mitos (LADVOCAT, 2002).

\section{Quadro teórico}

A adoção ocorre quando uma criança é levada para dentro de uma família por um ou mais adultos que não são seus pais biológicos, mas que, por força da lei, são reconhecidos como seus pais (KAPLAN; SADOCK; GREBB, 2003). A adoção, segundo Ayres (2009, p.19), "é entendida como ato jurídico pelo qual se estabelece, independentemente da biologia ou da genética, o vínculo de filiação." Souza (2009, p.17) aponta que "adoção vem do latim, adoptione, escolher, adotar". É um ato jurídico pelo qual o vínculo de filiação é criado artificialmente, gerando, sem consanguinidade, o parentesco de primeiro grau em linha reta descendente.

Levinzon (apud FARIAS e MAIA, 2009) define adoção como uma maneira de oferecer a uma criança que, por alguma razão não pode ser criada pelos pais biológicos, a 
oportunidade de ter uma família. Farias e Maia (2009) acrescentam que a adoção também representa a oportunidade de ter filhos para pais que não podem por motivos biológicos ou que optam por cuidar de crianças com quem não apresentam ligação genética.

Ladvocat (2009) lembra que o processo de adoção visa, em primeiro lugar, ao interesse da criança, à solução que melhor atenda aos seus interesses, isto é, ao ambiente familiar saudável e ao desejo legítimo para a adoção.

A adoção, conforme nos apontam Souza e Miranda (2011), envolve a importância da família no desenvolvimento infantil, pois é junto à família que as questões sociais e afetivo-emocionais se estabilizam, criando-se os vínculos necessários que asseguram a formação do indivíduo. De acordo com Levinzon (apud LIPP; MELLO; RIBEIRO, 2011), a adoção proporciona à criança uma família, de quem receberá carinho e cuidados para crescer saudável, incluída numa base social segura.

Para adotar, é necessário muito investimento afetivo e grande capacidade de acolhimento. Para Schettini (1998), não existem filhos que não sejam adotados, pois a adoção afetiva é o que constrói a relação parental. De acordo com Salzer (apud LADVOCAT, 2002), tanto os pais quanto os filhos adotivos criam um vínculo afetivo, e esse vínculo é uma espécie de cola emocional que ultrapassa a barreira da consanguinidade, sendo um sentimento intenso, seja pela criança biológica ou adotada.

Desde a antiguidade, a adoção está fortemente presente no cotidiano das sociedades. Muito utilizada entre povos orientais, tais como os gregos, era considerada uma forma de perpetuar o culto familiar pela linha masculina, ou, na hipótese de falecimento de pai que não deixara herdeiro, era tida como garantia de descendência (PICOLIN, 2007). No direito romano, um chefe de família sem herdeiros poderia adotar como filho um menino de outra família. O menino receberia o nome do adotante e herdaria seus bens, tornando-se o novo sucessor do trono (WEBER apud LADVOCAT, 2002). Já na Idade Média, sob a influência do Direito Canônico, que entendia ser a família cristã apenas aquela oriunda do matrimônio, a adoção caiu em desuso, ação justificada pelo receio de que pessoas dispensassem a união matrimonial para terem seus filhos (ARIÉS apud LADVOCAT, 2002). Com a Revolução Francesa, a adoção voltou à pauta, influenciando diversas culturas, inclusive a brasileira. A adoção foi conhecida também nas 
civilizações do Egito, da Babilônia, da Caldea e da Palestina. Passagens bíblicas relatam casos de adoção de Moisés pela filha do Faraó e de Ester que, conforme se extrai do velho testamento, foi filha adotiva (PICOLIN, 2007).

A adoção, segundo Weber (apud LADVOCAT, 2002), começou a ser vista como questão social e voltada para os interesses da própria criança a partir da Primeira Guerra mundial, devido ao abandono e à orfandade. Prossegue afirmando a autora que no início da Segunda Guerra mundial a legislação francesa introduziu a Legitimação Adotiva, que favorecia crianças menores de cinco anos, órfãos ou filhos de pais desconhecidos. No Brasil, a legislação sobre adoção começou a se estruturar no início do século XX com o Estado Moderno. Nesse mesmo período, a psicologia argumentava que a infância era a fase decisiva para a formação da personalidade adulta, e consequentemente de um desenvolvimento saudável. Assim, o Poder Público passou a entender que a inserção da criança em uma família seria importante para tornar o adulto mais produtivo (SILVA, 2009). No estudo da adoção no Brasil, são encontrados alguns exemplos, tais como da família da sociedade açucareira, que agregava filhos legítimos, ilegítimos, escravos, afilhados e filhos de “criação". Já na família indígena, a organização de parentesco se dava de forma peculiar, em que vários jovens eram irmãos sem vínculo genético (LADVOCAT, 2002).

No Brasil, desde 1988, com a Constituição Federal, extinguiu-se a distinção que havia entre filiação legítima e filiação adotiva, garantindo a todos os filhos os mesmos direitos e o mesmo tratamento legal (FARIAS e MAIA, 2009).

De um movimento social sem precedentes resultou a elaboração e a aprovação do Estatuto da Criança e do Adolescente (ECA) - Lei n 8.069, de 13/07/1990, que é considerada uma das leis mais avançadas do mundo em relação à infância (COSTA, 2004). A partir da vigência do Estatuto da Criança e do Adolescente em 1990, destaca Gueiros (apud LADVOCAT, 2009), a adoção passou a ser irrevogável, com a integração total do adotando na nova família, com direitos iguais aos filhos biológicos.

Farias e Maia (2009) afirmam que, conjuntamente à Constituição, o Estatuto da Criança e do Adolescente e o Código Civil legitimaram a filiação adotiva ao anular o 
registro de origem da criança, criando um novo registro de nascimento com o nome dos pais adotivos, integrando, assim, legalmente, a criança à nova família.

Conforme Ayres (2009), pelo Estatuto da Criança e do Adolescente, o Brasil firmou seu compromisso com a garantia de uma infância e juventude dignas, abolindo o termo "menor", substituindo-o pela expressão criança e adolescente. Essa lei propõe o redirecionamento da política de assistência e proteção ao segmento infanto-juvenil. Prossegue o autor afirmando que seu maior mérito e sua maior inovação foram a conceituação de crianças e jovens como sujeitos de direitos em processo de desenvolvimento.

O Código Civil de 2002, de acordo com Ayres (2009), fortaleceu e reafirmou a isonomia entre os pais, substituindo o conceito de pátrio poder para poder familiar; em seu texto, retira do pai a responsabilidade única pela manutenção, criação e educação dos filhos, delegando tais funções aos genitores (pai e mãe) indiscriminadamente.

Em 2009 é publicada a Lei da Adoção, lei n 12.010, de 03/08/2009, a qual, segundo Bochnia (2010), altera o Estatuto da Criança e do Adolescente, e a lei $n^{\circ}$ 8.560, de 1992; e revoga dispositivos da lei $n^{\circ} 10.406$ de 2002 (CÓDIGO CIVIL, 2002).

Alguns aspectos relevantes da Lei da Adoção (BRASIL, 2009):

- cria o Cadastro Nacional de Adoção - que reúne os dados das pessoas que querem adotar, e das crianças e adolescentes aptos para a adoção; estabelece uma preparação psicológica para esclarecer sobre o significado da adoção, e promover a adoção de crianças e adolescentes que não são normalmente preferidas (mais velhas, com problemas de saúde, indígenas, negras, pardas, e amarelas);

- aborda o conceito de família extensa (ou ampliada), deve esgotar as tentativas de a criança ou adolescente ser adotado por parentes próximos com os quais convive e mantém vínculos de afinidade e afetividade (tios, primos e cunhados têm prioridade na adoção, mas os ascendentes e os irmãos do adotando não podem adotar);

- estabelece a idade mínima de 18 anos para adotar, independente do estado civil (casado, solteiro, viúvo etc). Contudo, em se tratando de adoção conjunta (por casal), é necessário que ambos sejam casados ou mantenham união estável; 
- condiciona, se o adotado tiver mais de 12 anos, a adoção à sua concordância, em audiência;

- propõe a não separação de irmãos, que devem ser adotados pela mesma família;

- concessão à gestante que queira entregar seu filho (nascituro) à adoção de assistência psicológica e jurídica do Estado, devendo ser encaminhada à Justiça da Infância e Juventude;

- estabelece que crianças e adolescentes que estão em abrigos (acolhimento institucional) deverão ter sua situação reavaliada a cada seis meses, e que o prazo máximo de permanência no abrigo é de dois anos, salvo exceções;

- condiciona que a adoção internacional somente ocorrerá se não houver, em primeiro lugar, alguém da chamada família extensiva habilitado para adotar, ou, em segundo, ao fato de terem sido esgotadas as possibilidades de colocação em família substituta brasileira. $\mathrm{E}$ os brasileiros que vivem no exterior ainda têm preferência com relação aos estrangeiros (BRASIL, 2009).

O Brasil viu, nos últimos tempos, surgir uma nova cultura de adoção, que busca famílias para crianças, e não crianças para famílias, tendo, assim, um novo projeto de família, de maternidade e paternidade, atribuindo novos sentidos ao ser pai e mãe, distinto do tradicional modelo associado aos laços sanguíneos (COSTA e FERREIRA, 2007). Com o apoio do Judiciário, essa nova cultura da adoção busca fomentar às famílias as adoções diferenciadas, como as adoções tardias, de grupos de irmãos, de crianças com necessidades especiais, portadoras do vírus HIV e as adoções inter-raciais (FREIRE apud COSTA e FERREIRA, 2007).

Weber (2010) relata que no Brasil há uma cultura na qual se prioriza e valoriza a consanguinidade e as características físicas entre pais e filhos. No cotidiano, é comum vermos situações em que filhos são diferentes de seus genitores, mas as pessoas fazem questão de "ver" tais semelhanças, enfatizando assim a força dos genes. Ainda conforme a autora, se não houver preparação para lidar com essa questão, tanto pessoal, quanto em relação aos outros, os pais adotivos também poderão sofrer por não haver uma semelhança com seus filhos adotivos. Há também as questões dos traços hereditários, pois há dúvida sobre o que é herdado e o que é influência do ambiente, mas a ciência 
ainda nada provou a esse respeito e, mesmo quando o fizer, será muito difícil determinar com clareza o quanto de um traço de personalidade é fruto da genética e em que proporções (WEBER, 2010). Para Weber (2010), o que ocorre é certa comodidade em relacionar tais características comportamentais à hereditariedade, o que acaba por isentar as pessoas da responsabilidade de ter contribuído ou construído tal comportamento.

Coehen, Coyne e Duvall (apud LADVOCAT, 2002) explicam que a adoção está registrada no psiquismo da criança. A partir da adoção, os pais e a criança passam a reescrever a sua historia familiar, mas também na sua biografia pré-adotiva estão incluídos muitos momentos, como: gestação, nascimento, contato com sua genitora, o rompimento desse contato, a instituição que a acolheu, o encontro com os pais adotivos, e toda a história que se desenvolve com sua nova família (LADVOCAT, 2002).

Há pessoas que não conseguem, pelas vias biológicas, ter um filho, e diante dessa impossibilidade surge a motivação para a adoção, no intuito de que possam se constituir como família e com filhos (LADVOCAT, 2002). De acordo com Dell Antonio (apud LADVOCAT, 2002), o casal, diante da sua infertilidade, precisa fazer uma elaboração, a qual é considerada uma passagem indispensável para a adoção bem sucedida.

Conforme Weber (apud LADVOCAT, 2002), com base em um estudo sobre as motivações para a adoção realizado com 240 pais adotivos, 63\% desses revelou ter adotado um filho para resolver uma necessidade em sua vida, como a infertilidade, estado civil de solteiro ou morte de um filho, e 34\% desses pais apontou motivações altruístas, como de ajudar uma criança considerada "abandonada”.

De acordo com Villa (apud LADVOCAT, 2002), deve-se verificar se a motivação da adoção se dá pela ordem do desejo, ou da necessidade de uma criança, conceitos que, não raramente, são confundidos como sinônimos. Ainda conforme a ideia do autor, a necessidade vem de uma carência, e assim quem adota, está buscando uma completa satisfação, não conhecendo a lei nem a moral; já o desejo é uma livre escolha, e marca a construção de um novo relacionamento, porquanto se uma mãe deseja um filho, ela ampara suas angústias, mas se ela tem necessidade do filho, procura nele, mesmo que inconscientemente, a satisfação de suas próprias necessidades. Dell Antonio (apud 
LADVOCAT, 2002) também concorda que o filho deve ser considerado como "filho do desejo" e não como "filho da necessidade", pois a criança não pode nascer predestinada a resolver conflitos dos seus pais.

O tempo de espera para adoção de uma criança pode ser comparado com a gestação biológica, mas a gestação adotiva se desenvolve a partir de uma vivência intrapsíquica e de um desejo no processo da adoção (LADVOCAT, 2002). Os vínculos da relação afetiva e familiar se desenvolvem através da convivência. (WEBER apud LADVOCAT, 2002).

Dolto (apud LIPP; MELLO; RIBEIRO, 2011) traz algumas contribuições na compreensão da adoção, afirmando que não há uma idade específica para a revelação de uma adoção. Ele ressalta, aliás, que essa situação jamais deve ser escondida, mesmo que a criança ainda não entenda bem o significado da palavra. A verdade deve ser anunciada e contada à criança e às pessoas que fazem parte do círculo de relações desses pais de maneira natural e verdadeira.

Sanches (apud LIPP; MELLO; RIBEIRO, 2011) ressalta que a dificuldade de revelar a adoção é uma questão dos adultos que, uma vez atravessados pelo discurso social, defendem a ideia de que como a criança já sofreu muito com o abandono da mãe biológica, é permitido, então, aos pais, omitir a adoção e silenciar-se frente a essa difícil história, como se, com isso, pudessem poupá-la do sofrimento.

Julien (apud LIPP; MELLO; RIBEIRO, 2011) afirma que todo o bebê, pouco após o nascimento, evidencia a angústia em relação ao desejo do Outro Materno representada pela interrogação: "O que quer ela de mim?". Da mesma forma, essa interrogação se inscreve na criança adotada quando seus pais adotivos a levam para casa. Hoyer (apud LIPP; MELLO; RIBEIRO, 2011) destaca que, contudo, antes mesmo do nascimento, ou de uma adoção, a criança já é imaginada, falada e sonhada como resultado do desejo inconsciente do Outro Primordial, encarnado pela mãe.

No Brasil, quando o processo de adoção está em andamento, permanece disponível aos postulantes à adoção o histórico da criança. Com o término do processo, esses dados são selados e, dessa forma, não se tem mais acesso a informações sobre a origem biológica do adotado, o que se justifica pela intenção de proteger a criança do 
estigma do "diferente", e também os pais adotivos, para que não possam sofrer interferência da família de origem. Isso tudo, no entanto, não significa a negação da história pré-adotiva, tampouco a necessidade de a criança ser protegida dos riscos do diálogo com seus pais adotivos sobre sua história. Os registros fechados visam garantir à criança uma certidão de nascimento sem dados que sinalizem que ela é adotada, sem colocá-la como "diferente" das crianças que têm laços sanguíneos com seus pais (LADVOCAT, 2002).

A história biológica da criança visa completar dados para construção de sua identidade, a partir de dados de realidade. Caso não se tenha informações sobre seu período de vida antes da adoção, é necessário elaborar esse fato e tratar tal elaboração como realidade da sua história (LADVOCAT, 2002). Mesmo quando a adoção é revelada, o tema é, por vezes, por uma série de razões, transformado em tabu, afirma Ladvocat (2002), uma vez que os pais ficam constrangidos toda vez que o assunto é mencionado, e a criança fica assim aflita por não poder fazer perguntas sobre sua história.

Videla (apud LADVOCAT, 2002) salienta que quando se oculta da criança a verdade sobre a adoção, se produz um vazio na sua história. Alguns pais adotivos têm medo de que um dia a família biológica entre em contato com a criança e, com base nesse temor, evitam conhecer a genitora na hora da adoção; optam pela omissão de informações sobre a origem da criança; buscam a criança numa região bem distante da onde moram, e preferem dizer que os pais biológicos morreram (LADVOCAT, 2002).

Para Hartman (apud LADVOCAT, 2002), o segredo pode criar na criança uma dificuldade de pertencer à sua família, e nos pais pode afetar seus sentimentos de competência e direitos adquiridos ou negados.

Todos os membros da família conhecem a história da adoção, porém, existe uma proibição - que pode ser explícita ou implícita - de comentar sobre o tema, o que faz com que algumas crianças acabem desenvolvendo sintomas como distúrbios de aprendizagem, justificados pelo fato de que a aquisição de conhecimento está voltada à curiosidade sobre sua origem (LADVOCAT, 2002).

Quando a adoção é abordada como algo natural, aberta a questões sobre sua origem, é a base para o relacionamento saudável entre pais e filhos, mas quando tratada 
em forma de segredo, pode sim ocasionar problemas por ser vista como assunto proibido e repleto de crenças e mitos. Assim, pode-se buscar ajuda de profissionais para auxiliá-los nesse processo (LADVOCAT, 2002).

De acordo com Alvarenga (apud LADVOCAT, 2002), os pais adotivos sabem da importância da adoção e sua origem, mas sentem-se confusos sobre o tema, e ficam receosos de que a criança sofra em entrar em contato com a história da família biológica.

Os pais devem, desde cedo, conversar com o filho sobre a adoção, tentando abordar o assunto da maneira mais tranquila, segura e confiante possível. Dentre os muitos elementos que justificam essa escolha, está o fato de que há que se considerar que sempre existe a possibilidade de a criança ficar sabendo da adoção sem querer, por outras pessoas que não sejam os pais. E se essa descoberta se der a partir da revelação, ou do envolvimento de terceiros, poderá implicar o surgimento de um sentimento de traição, de enganação que, por sua vez, pode implicar a perda da confiança nos pais (ROSAS, 2012). De acordo com Weber (apud ROSAS, 2012), quando a revelação da adoção ocorre de forma tardia ou inadequada, os riscos de conflitos familiares são muito sérios.

Dados clínicos evidenciam que a "mentira" dentro do contexto familiar, principalmente quando omite ou nega as origens de uma criança, atua como um fator que leva a situações patológicas. Assim, embora a publicização da adoção não seja exigência legal, é muito importante que a revelação da verdade ocorra em âmbito privado, isto é, na família (TRAVASSOS, 2012).

Não existe idade ideal para revelar à criança o tipo de vínculo que tem com seus pais adotivos, mas é de suma importância que os pais já contem historinhas de adoção e exibam filmes infantis com essa temática desde a sua chegada à família, independente da idade. Dessa forma, ela vai se acostumando com o tema, e entendendo os fatos na medida em que for amadurecendo (SILVA, 2012a). Alguns pais, de uma maneira equivocada, percebem a adoção como algo negativo, mas não é necessário que a criança tenha essa mesma compreensão. O adotado somente repetirá esse modelo de conduta se os pais insistirem nesse erro, tratando a adoção como algo vergonhoso e negativo (SILVA,2012a). 
Os filhos adotivos também sofrem pelo preconceito social, e também aderem ao modelo transmitido por seus pais, demonstrando que não sentem curiosidade nem interesse em saber sua própria história, ou de seus pais biológicos. O que ocorre é um acordo implícito e velado para não se falar a respeito da adoção: os pais então procuram negar sua esterilidade e/ou o medo fantasioso de que o filho volte para sua família biológica; os filhos, por sua vez, não falam a respeito para não magoar seus pais, e para encobrir a mágoa de ter sido rejeitado por sua família de origem e, assim, perdem um pedaço de sua identidade (SILVA, 2012a).

De acordo com Eldridge (apud SILVA, 2012a), a criança adotiva raramente fala de forma aberta sobre sua raiva relacionada ao fato de ser adotada, por acreditar que estará magoando os pais adotivos, e por achar que os deixará incomodados. Ela, assim, acaba não falando sobre a adoção, e pode expressar isso de uma forma agressiva, e pode ter dificuldades de socialização em algum momento. Muitas vezes, na adaptação, pode apresentar um comportamento inadequado por querer mostrar que há algo de errado com ela, por estar sofrendo algum tipo de privação, ou sofrendo com algum sentimento com o qual não está sabendo lidar.

No período de convivência com a família adotiva, a criança passa por algumas fases: i) Fase do encantamento: faz de tudo para agradar os pais e se sentir parte da família - geralmente ocorre no período de adaptação; ii) Fase de testes: passa a testar os novos pais, com provocações, agressividade, para ver se os pais realmente a amam, ou se irão abandoná-la; iii) Regressão: passa a agir como um bebê, a fazer xixi na cama, a pedir colo, ou querer usar a chupeta, tentando, assim, vincular-se com a nova família e renascer dessa nova mãe; iv) Adaptação: precisa de tempo para se adaptar com os novos hábitos e costumes de sua família (VEIGA, 2013).

Ladvocat (2002) ressalta que geralmente os filhos adotivos não querem de fato encontrar seus genitores, e sim ter informações sobre sua história, saber por que não puderam ficar com a sua família de origem, e por que foram colocados para adoção, para, assim, preencher as lacunas em branco de sua biografia, e conectar com sua história atual. Essas informações sobre a origem podem e devem ser acessadas à medida que a criança manifestar curiosidade, e tiver maturidade para compreendê-las. Tanto os pais 
precisam reconhecer que houve um tempo antes da adoção, como a criança também precisa aceitar esse tempo como parte de sua trajetória de vida (LADVOCAT, 2002). Já no que diz respeito à revelação sobre a adoção, destaca Ladvocat (2002) que esta deve ser feita desde a chegada da criança na sua família adotiva.

Também de acordo com Videla (apud LADVOCAT, 2002), a revelação das origens deve ser realizada com o devido cuidado, respeitando o tempo lógico e real da criança, da mesma forma que fatos da vida como morte, sexualidade, nascimento de bebês devem ser informados à criança, sempre de acordo com sua curiosidade, e com sua capacidade de absorver essas informações.

Quando há interesse do filho adotivo em ter informações sobre sua origem, e os pais adotivos não sabem o que contar, esse pode ser um momento marcado por conflitos, afirma Schettini (apud LADVOCAT, 2002), já que o filho quer respostas sobre os seus genitores.

\section{Metodologia}

A pesquisa que gerou este artigo é de caráter qualitativo, e pelas suas propriedades se insere na modalidade da pesquisa ação, pois à medida que vai colhendo os dados, interfere nas realidades, propondo mudanças no mundo real, compromete-se com um campo restrito, e submete-se a uma disciplina para alcançar os efeitos do conhecimento (CHIZZOTTI, 2001).

Foram realizadas entrevistas semiestruturadas com cinco participantes que fizeram acompanhamento no "Projeto de Extensão de Terapia Familiar com Famílias Adotivas", no Centro de Psicologia Aplicada de uma instituição de ensino superior do sul do Brasil, no período de agosto a dezembro de 2012.

As pessoas entrevistadas receberam o Termo de Consentimento Livre e Esclarecido, documento que, entre outros propósitos, esclarecia os objetivos da pesquisa, e o fato de que a participação dos sujeitos na pesquisa era voluntária.

Os sujeitos foram contatados por telefone antes das entrevistas, ação cujo escopo consistia em explicar os objetivos da entrevista, e responder eventuais dúvidas que esses sujeitos pudessem ter sobre os procedimentos. Com aqueles que voluntariamente 
aceitaram participar, foi marcado o dia da entrevista, em horários que atendessem sua disponibilidade de agenda.

As entrevistas foram realizadas no ambiente de trabalho dos participantes, e também no Centro de Psicologia Aplicada, de acordo com o que Ihes parecia mais cômodo. Foram gravadas e depois transcritas para a análise. Posteriormente as gravações foram destruídas.

$\mathrm{Na}$ análise de conteúdo foram levantadas categorias que foram analisadas em relação com a teoria, partindo-se, assim, para uma compreensão dos fatores marcantes na opinião das famílias sobre a revelação da adoção e suas origens. Foram quatro categorias desenvolvidas para análise:

Categoria 1- Mitos ou preconceitos sobre fazer ou não a revelação da adoção e da historia pré-adotiva;

Categoria 2- Se contaram ao filho que é adotado e sua historia pré-adotiva, como contaram, que idade tinha a criança, e quem participou do momento da revelação;

Categoria 3- Os sentimentos vivenciados no momento da revelação;

Categoria 4- Dificuldades encontradas na revelação da adoção.

\section{Análise e interpretação dos dados}

Apesar de a adoção ser uma prática antiga, ainda há muitos preconceitos que ocasionam possíveis mitos e fantasias nas relações de pais e filhos adotivos, pois,infelizmente, na sociedade contemporânea, ainda há dificuldade de lidar com o que é diferente do habitual, tais como os laços que vão além do biológico. Para verificar esses aspectos da adoção, foram coletados dados nas entrevistas, obtendo-se um resultado positivo, uma vez que, apesar de ficarem ansiosos com a revelação da adoção e de sua historia pré-adotiva, optaram por manter a relação através da verdade, não se deixando influenciar pelos tabus criados pelas outras pessoas. Foi criada, então, a Categoria 1 Mito ou preconceitos sobre fazer ou não a revelação da adoção e da historia pré-adotiva.

Por mais que a maioria dos entrevistados sinta-se insegura em abordar o tema, eles sabem da importância da revelação da adoção para seus filhos, e, mesmo com seus medos sobre como a criança vai entender a condição da adoção e suas fantasias de 
abandono, sabem que a melhor forma de lidar com a situação é através da verdade. Consideram que o diálogo com o filho sobre a adoção proporciona o desenvolvimento saudável na relação pais e filhos, fortalecendo a confiança entre estes e fazendo com que o assunto não se torne um tabu dentro da família, mas algo que possa ser "evocado" em qualquer momento.

Um dos entrevistados sente dúvida em como melhor contar: "não sei se doso ou conto tudo, ele não pergunta muito para nós". Eldridge (apud SILVA, 2013) aponta que um dos motivos para a criança não falar sobre a condição da adoção é que a dor que acompanha a perda é difusa, sutil, e difícil de colocar em palavras. Como já citado, quando o filho não demonstra curiosidade, nem interesse em saber sua própria história, ou de seus pais biológicos, o que ocorre é um acordo implícito e velado para não se falar a respeito da adoção: os pais então procuram negar sua esterilidade, o medo fantasioso de que o filho volte para sua família biológica; os filhos, por sua vez, não falam a respeito para não magoar seus pais, e para encobrir a mágoa de ter sido rejeitado por sua família de origem e, com isso, perdem um pedaço de sua identidade (SILVA, 2012a).

O mesmo entrevistado fala também sobre o vínculo com o filho: "O mito de que o vínculo entre a criança e os pais é difícil não se sustenta, pois senti muita saudade enquanto estava numa viagem". De acordo com Silva (2013d), essa crença referente à dificuldade do vínculo é fruto de fantasias nascidas dos preconceitos.

Outro entrevistado tem receio de como a filha vai lidar com a condição da adoção: "tenho medo dela não aceitar a condição de paternidade, que possa apresentar algum comportamento inapropriado ao receber a notícia”. Outra entrevistada também tem medo que o filho possa ficar triste ao saber que é adotado, e diz “... que ele não nasceu de dentro de mim, de dentro da minha barriga". Sentimentos de rejeição e abandono assombram o imaginário dos pais sobre a revelação da adoção, mas, após o tempo necessário para a acomodação das emoções vivenciadas, os laços entre pais e filhos se fazem por um arranjo muito mais forte de amizade, amor e confiança (SILVA, 2013d). Schettini (2013) relata que o desconforto vivenciado pelos pais na hora da revelação da adoção faz com que pareça que o que será revelado possa destruir o afeto familiar. 
Porém, as dificuldades nas relações interpessoais poderão surgir muito mais pela manutenção dos segredos do que pela revelação da verdade.

Outra entrevistada, por já ter um filho adotivo, sente-se mais tranquila em falar sobre o assunto, e afirma: “... eu vou ensinando conforme ela vai tendo curiosidade...”, mas ainda não se sente tranquila em relação à filha conhecer sobre a família biológica, embora esteja ciente de que em algum momento isso possa vir à tona. Afirma ter receio disso: "eu sei que vai acontecer, que em algum ponto ela queira ou não, não tenho a preocupação de que ela vai me trocar, até acho que pela minha experiência anterior...”. Ao optar pela adoção, os pais adotivos devem levar em conta que estarão sempre ligados aos pais biológicos de seus filhos, porque, sem estes, seus filhos não estariam no mundo hoje (SCHREINER apud SILVA, 2013a). Para Eldridge (apud SILVA, 2013a), a criança precisa sentir que os pais adotivos têm uma relação de respeito com seus genitores, assim, eles podem auxiliar o filho a integrar e aceitar a sua família biológica, reconhecendo o seu valor como parte inicial. A filiação dupla será vivida de maneira integrada e saudável, pode ser que se saiba quase nada ou muito, ou até mesmo algo muito triste, que não demande detalhamento, mas o que importa é que essa história anterior existe, que não pode ser modificada, e deve ser respeitada (SILVA, 2013a).

Este momento da revelação da adoção e sua historia pré-adotiva vem acompanhado de muita ansiedade e fantasias pelos pais adotivos, pois ficam em dúvida sobre quando e como revelar ao filho a sua condição de adotado. Nesse sentido, foram investigadas outras questões, que permitiram a construção da Categoria 2 - Se contaram ao filho que é adotado e sua historia pré-adotiva, como contaram, que idade tinha a criança, e quem participou do momento da revelação.

Todos os entrevistados já contaram sobre a adoção para os filhos. Em alguns casos a revelação foi feita pelo o casal, em outros, só pela mãe, mas o assunto é conhecido por todos da família. Por serem adoções ocorridas já numa idade mais avançada da criança, alguns, já contaram desde sua chegada ao novo lar. Já os outros começaram a contar uma historinha sobre sua chegada à família, mesmo quando ainda bebês, para que o assunto pudesse se tratado de uma maneira natural. Essa atitude é revelada na ação de 
uma das crianças, que, com 3 anos e 11 meses na ocasião da entrevista, já conta sua própria historinha.

É muito importante que os pais falem sobre a adoção para os filhos, não importando a idade. A forma lúdica, através de historinhas, se revela como sendo uma maneira de fácil compreensão para a criança, pois, por mais que a criança não tenha maturidade suficiente para entender o sentido de ser adotada, isso já vai ficando gravado nas suas memórias. E quanto mais maturidade tiver, melhor vai poder elaborar sua história, tanto a pré-adotiva quanto a atual. Também se ressalta que é um assunto para ser tratado de forma espontânea e sem preconceitos, deve sempre ter acesso livre entre as pessoas envolvidas, o que reforçará o sentimento de confiança e de pertencimento na família, tanto dos pais quanto dos filhos.

Um entrevistado relata que a conversa sobre a adoção foi feita pelo casal logo após a conversa que tiveram com a psicóloga do Fórum, quando a criança estava com 5 anos e 6 meses: "ele pediu se era filho da barriga, e dissemos que era filho do coração". Revelou também já ter falado sobre a história pré-adotiva, destacando que os genitores não puderam cuidá-lo, e que ficou um tempo com a genitora e a avó materna, tendo, em seguida, ido para a Casa da Criança (abrigo). Outro entrevistado conta que também o casal está contando para a filha a história de como chegou até eles, a partir dos 3 meses de idade: "como ela ainda é bebê começamos a contar de uma forma lúdica". Outra entrevistada, também pelo fato de o filho ser bebê, já vai contando de uma forma lúdica, o que também é feito por uma tia da criança: "na verdade não vai ter uma data específica, não vai ter um dia, desde sempre vou falando para ele, que ele é um presente... que tava esperando por ele há 4 anos, que tínhamos pedido para o papai do céu...". Uma entrevistada destaca que é ela que conta a historinha da adoção para a filha desde quando ela tinha um ano, na hora de dormir, e quando pedia para contar historinhas: "porque tem que fantasiar um pouco enquanto são pequenos para eles conseguirem entender, então eu fico com o protocolo do primeiro que deu certo... conto para ela assim: que a mamãe já tinha dois meninos e queria muito uma menininha, só que na barriga da mamãe tava complicado, pedi para Jesus e ele mandou você por outra barriga, a mamãe foi longe para te procurar, até que a mamãe encontrou você...". Refere ainda 
que agora ela mesma já conta a sua própria historinha, só que ao contrário. Outra entrevistada também conta para o filho uma história lúdica, desde quando a criança tinha 3 anos de idade: "uma moça que encontrou um moço e eles se apaixonaram... daí cresceu um nenezinho na barriga dela... só que o moço precisou ir embora e não podia cuidar do bebê, e a moça tinha um dodói e não pode também cuidar do bebê, então o amigo juiz o levou para a casa da criança... como o juiz sabia que ela queria muito um filhinho chamou e a levou conhecer o bebê, e o bebê conheceu a mamãe e foi morar com ela, daí conheceu a priminha, os tios, avós e eles estão felizes" . Coloca que não faz nenhum mistério, inclusive porque ele não é a primeira criança adotada na família.

Do ponto de vista psicológico, Schettini (2013) afirma que é preciso ouvir a nossa própria história para ouvir a nós mesmos, e destaca que não importa que a verdade tenha aspectos desconfortáveis, pois essa não machuca quando vem acondicionada no afeto. Como já foi citado anteriormente, não existe idade ideal para a criança saber sobre o tipo de vínculo que tem com seus pais adotivos, mas é importante e saudável que os pais lhe contem historinhas de adoção desde a sua chegada à família, independente da idade, para que, dessa forma, o adotado já se acostume com o tema, e entenda os fatos e seus significados na medida em que for amadurecendo. Tal postura fará com que essa criança sinta que seus pais adotivos sempre foram sinceros sobre a sua adoção, e que o assunto é conhecido e permitido no âmbito familiar (SILVA, 2013C).

Schreiner (apud SILVA, 2013d) acrescenta que em toda história há riqueza, porque há vida e experiência. Destaca que são nossas histórias de vida que nos tornam diferentes, especiais, que nelas há sempre um ensinamento, uma lição, o que faz com que mereçam respeito. Para haver uma adoção, deve ter havido, antes, um abandono, e por menos sofrido que isso tenha sido, há sempre uma história relacionada. Um filho adotivo sempre terá uma história anterior à adoção, que deve ser respeitada, por fazer parte dele, por tê-lo ajudado a se formar (SCHREINER apud SILVA, 2013).

De acordo com Hartman (apud SILVA, 2009b), pesquisas científicas revelam que pais adotivos que conversam abertamente e compartilham informações criam adultos mais seguros, e com um senso firme de self. Silva (2009a) afirma, sobre os 
aspectos da adoção, que a criança deve sentir que sua chegada ao mundo foi um acontecimento especial, e que a sua história de vida vale a pena ser contada.

Sendo a revelação da adoção acompanhada de diversas emoções e sentimentos, foi pesquisado o que esses pais sentiram e vivenciaram nesse momento. Com base nas entrevistas, foi criada a Categoria 3 - Os sentimentos vivenciados no momento da revelação.

Considerando o fato de que cada pessoa é única e tem experiências de vida diferentes, cada um percebeu essa questão também de maneira diversa: sentimentos de realização na questão da paternidade, e dúvidas sobre a melhor maneira de educar; satisfação por estar sendo sincero com o filho; sentimento de tranquilidade e segurança, quando já teve bom êxito com a primeira adoção; angústia e confusão ao contar a historinha para o filho, como se estivesse contando algo que não é real; sentimento de que gestou o filho; sensação de que ele esteve a vida toda com a família, e não apenas há um ano.

Sentir dúvida de qual será a melhor maneira de educar o filho, transmitir valores e limites é algo natural, e traz uma inquietação que tanto pais biológicos quanto adotivos vão ter no decorrer do desenvolvimento da criança. Realizar-se como pai/mãe é algo que surge quando há o desejo, e não apenas a necessidade, pois esta, por vezes, remete a uma falta, o que pode vir a atrapalhar o relacionamento afetivo entre pais e filhos. Nesse sentido, foi possível perceber, durante as entrevistas, esse desejo da parte dos adotantes. Percebeu-se que situações anteriores de adoção se consolidaram como facilitadoras em todo o processo, desde a revelação para a criança até o agir diante das outras pessoas que abordaram o tema, e também questões ligadas à educação. Algumas mães sentem como se o filho estivesse a vida toda com elas. Esse sentimento talvez esteja relacionado à gestação emocional, pois enquanto estavam na fila de espera, o filho já estava sendo gerado no seu psiquismo, o que pode ter facilitado o vínculo com a criança, pois havia grande desejo e amor já na espera.

Um dos entrevistados refere três sentimentos no momento da revelação: “Primeiro: realização, olhar para um serzinho que tá ali dormindo, e ver que pode dar um lar a ele. Segundo: medo se está fazendo a coisa certa em relação à educação, encontrar 
um equilíbrio entre limites e ser liberal. Terceiro: medo de perder, se ver amando de verdade." Os sentimentos vivenciados são naturais do processo da paternidade e filiação, pois tanto pais biológicos quanto adotivos sentem-se realizados com a chegada do filho à família, ambos passam pela inquietação a respeito da melhor forma de educá-los, e consequentemente também fantasiam perder o amor dos filhos quando colocam os limites. Compreende-se a preocupação do pai quando relata que tem medo de perder o filho, receio esse advindo do fato da demora da documentação legal pelo Poder Judiciário.

Outro entrevistado relata ter um "sentimento agradável por contar a verdade". Qualquer relacionamento precisa ter como base a empatia, pois assim conseguimos nos colocar no lugar do outro, o respeitamos. Dessa forma, assuntos a serem tratados no âmbito familiar, por mais difíceis que possam ser, quando abordados de maneira verdadeira, são mais fáceis de serem compreendidos, ainda mais quando acompanhados por afeto.

Uma entrevistada relata "Fico muito emocionada, às vezes dói o meu coração, me dá uma angústia, um aperto, para mim não faz diferença ele não ter nascido de dentro da minha barriga... com o passar do tempo, a sensação que ele nasceu de mim mesma, estou com ele desde recém-nascido tinha 16 dias... quando vou contar essa história para ele, me dá uma angústia porque tenho a sensação de que estou mentindo... Essa sensação que me angustia, me parece de estar contando uma coisa mentirosa, mas é verdade, é que a gente ama tanto." O vínculo, quando bem estabelecido, nos dá a sensação de longo prazo de convivência. No caso dessa mãe, além do vínculo formado, o filho está com ela desde bebezinho. Há também o fato de ela ter ficado por quatro anos na fila de espera para adotar, período em que, como afirmado alhures, ocorre a gestação emocional.

Outra entrevistada diz que "Como ela foi a segunda experiência, foi mais tranquilo, eu segui o que tinha dado certo com o mais velho... eu já tinha na mente como que eu ia fazer, claro que cada um tem um jeitinho.... Lá em casa aconteceu de ser diferente o biológico, acho que ele que vai ter que ir no psicólogo, ele é mais enciumado do que os outros." Experiências anteriores trazem mais autoconfiança no momento de dialogar com o filhos sobre a adoção, pois a ansiedade está reduzida, e possíveis mitos 
são desmistificados. Acredita-se ser importante que pais adotivos, se não tiverem experiência de adoção na própria família ou na família extensiva, possam buscar em circulo de amizades, ou em grupos de apoio, contato com pessoas que adotaram, pois assim como a entrevistada, passam a se sentir mais tranquilos e seguros em lidar com questões pertinentes à adoção e ao desenvolvimento da criança.

Uma entrevistada conta: "Para mim não parece que faz só um ano que ele está comigo, parece que ele esteve a vida toda comigo, então eu não tenho muito sentimento assim: ai ele é adotado, ele veio, a sensação que eu tenho que ele esteve comigo sempre”. Ressalta-se novamente aqui que a questão do vínculo é de extrema importância nas relações, pois estabelece a empatia, o afeto, a união entre pais e filhos, o que resulta na sensação de longo período junto com a criança.

Silva (2010b) refere que as pessoas adotam para satisfazer o seu desejo de serem pai e mãe, de terem um filho, de aprenderem, ensinarem e passarem por todas as alegrias e dificuldades de uma parentalidade como na biológica. Não há diferença, com exceção da existência de uma história pregressa do filho, e todas as particularidades que esta possa representar, e só. O amor é igual, o apego, a necessidade de proteger e ser protegido é igual (SILVA, 2010b).

Esse momento é, portanto, marcado por ansiedade, dúvidas e alegrias, mas também é marcado por algumas dificuldades, já que cada indivíduo tem sua subjetividade, e sua história de vida também vai influenciar nessas questões. Com base nessa questão, foi construída a Categoria 4 - dificuldades encontradas na revelação da adoção.

Através das respostas dos entrevistados, percebe-se que não encontraram muitas dificuldades na revelação da adoção aos filhos. Cabe ressaltar que todos os entrevistados participaram do Projeto de Extensão do Curso de Psicologia da Universidade de Passo Fundo denominado Terapia Familiar com Famílias Adotivas. Nessa atividade de extensão, os entrevistados receberam acompanhamento durante o estágio de convivência, onde puderam ser ouvidos sobre suas dificuldades de adaptação, e sobre a nova condição adotiva. Receberam informações sobre a revelação da adoção, e puderam falar sobre os mitos e preconceitos que acompanham o processo adotivo. 
Dois entrevistados não escolheram um momento específico para fazer a revelação, e revelaram estar construindo com os filhos a sua história, contando historinhas de como eles chegaram até a família, fazendo isso de maneira espontânea e afetuosa. Por mais que se sintam inseguros em relação à melhor forma de educar, de falar sobre as origens, e também de como os filhos vão perceber a condição da adoção quando estiverem na fase escolar e na pré-adolescência, não deixam de falar sobre o assunto. Dessa maneira, possibilitam que a relação seja transparente, e que a história seja contada e recontada quantas vezes for preciso. A forma como os pais percebem a adoção e as questões que os levaram a adotar vai determinar a forma como vão lidar com a situação, e como tratarão do assunto com os filhos.

Um entrevistado diz "A revelação foi acontecendo de maneira natural e não ritualizada, se reduzindo ao amor... a revelação foi um momento importante, mas o casal procurou fazê-la de forma natural... Sentiram dúvidas em relação à educação, valores, limites, fases de desenvolvimento, usar uma linguagem adequada para usar com a criança de uma forma que ela entenda." Relatam que ao receberem a guarda, sentiram um alívio, e que após esse momento, o tema da revelação se tornou mais presente. Não se deixaram tomar pela ansiedade, podendo assim se manter mais tranquilos, o que facilitou a ocorrência de um diálogo de forma espontânea com o filho, o que é facilitado pela presença da verdade e dos limites, acompanhados pelo afeto. Mantiveram cuidados com o bem-estar e com a saúde emocional do filho, e estiveram atentos a questões que envolvem a adoção, como a educação, o que acontece em determinada fase do desenvolvimento, o uso de uma linguagem que facilite a compreensão do que está acontecendo.

Outro entrevistado afirma que não encontrou dificuldade: "No momento nenhuma por ser bebê. Receio se ela vai querer saber de toda a sua história, dos genitores, guardamos certidão de nascimento antiga para mostrar a ela." Como o assunto vem sendo abordado desde a fase em que o filho ainda é bebê, isso se torna um facilitador nas conversas futuras sobre a adoção. Outra entrevistada também revela não ter, até então, encontrado nenhuma dificuldade na revelação, uma vez que seu filho também é bebê, mas se preocupa quando ele for à escola, quando pedirem fotos da 
barriga da mãe: "isso é uma coisa que me preocupa, porque eu não vou ter para dar para ele, eu penso como ele é criança quando pedem isso, penso que ele possa ficar constrangido com essa situação de não ter a foto da barriga, do nascimento... não sei o que fazer - contar ou não contar na escola, contar para a diretora na hora de fazer a matrícula para ele não ter que passar por esta situação, ou não contar para preservar ele".

Conforme citamos anteriormente, o assunto sempre se torna natural e de fácil diálogo quando abordado desde cedo. Esse receio de quando ele for à escola e pedirem a foto da barriga é uma preocupação que os pais têm para que as crianças não se sintam desvalorizadas diante dos outros, por ter vindo à família de uma forma diferente do que é compreendido como convencional. No entanto, quando o assunto é abordado desde cedo, e com base na verdade, a criança sente orgulho da sua história, e não tem receio de expor sua chegada à família para as outras crianças, merecendo destaque o fato de que crianças podem ser muito empáticas umas com as outras.

Outra entrevistada relata: "Não tive dificuldades, porque com a menina a historinha já estava montada, segui a historinha que contei para o mais velho e que deu certo." O êxito com a primeira adoção fez essa mãe se sentir segura, tranquila, no momento em que foram feitas as conversas sobre a adoção, o que permitiu passar para a filha esse sentimento de segurança e tranquilidade.

Outra entrevistada seguiu a sugestão de uma amiga que também tem filhos adotados para contar a historinha para ele: "Daí eu disse: bom, é uma maneira tranquila de fazer de uma forma lúdica para ele saber... Me preocupo que quando ele estiver na pré-adolescência, adolescência, isso não venha ser um problema para ele, que tenha isso bem tranquilo, sim eu fui adotado, mas tive a sorte de ter uma família." Seguindo a sugestão da amiga para contar a historinha, também sentiu-se mais tranquila e segura para ir falando sobre a adoção com o filho, já que sua amiga teve êxito com essa experiência com suas filhas também adotivas. Quando o assunto da adoção é conversado desde a chegada da criança à família, e não existe tabus para falar sobre a sua história pré-adotiva, a criança passa a compreender sua história de vida pré-adotiva e atual, 
podendo, assim, chegar à adolescência com essa questão resolvida para a construção da sua identidade.

Weber (apud ROSAS, 2012) refere-se a uma pesquisa que revelou que as relações entre pais e filhos adotivos são satisfatórias, pois a maioria deles não teve dificuldades na educação e no relacionamento afetivo com a criança. Algumas dificuldades encontradas por alguns pais adotivos no relacionamento com o filho foram provenientes de revelações tardias, ou feitas de maneira não adequada. De acordo com a mesma autora, alguns comportamentos apresentados como negativos nos relacionamentos de pais e filhos adotivos, como desobediência, rebeldia, maus hábitos, são, da mesma forma, apresentados na relação de pais e filhos biológicos. Não existem relações perfeitas, sem problemas, mas relações em que se deve aprender a lidar com as dificuldades que vão surgindo, pois, como disse Guimarães Rosa, "viver é muito perigoso" (WEBER apud ROSAS, 2012).

Weber (apud ROSAS, 2012) acrescenta que é possível que na adolescência, ou até mais tarde, o adotado viva o desejo de procurar sua família de origem, mas não é preciso temer a perda do afeto, pois a necessidade é de saber suas raízes para se fortalecer como adulto. Essa busca, na maioria das vezes, é simbólica e não traduz insatisfação com sua família adotiva.

\section{Considerações finais}

A realização deste estudo objetivou verificar de que forma os pais adotivos contam ou pensam em contar sobre a adoção e história pré-adotiva ao filho adotivo; seus possíveis medos e mitos relacionados à adoção, juntamente com sentimentos ou emoções que vivenciaram durante o processo da revelação.

Diferente do que a literatura mostra a respeito das dificuldades encontradas pelos pais adotivos para fazer a revelação da adoção, um dado muito relevante encontrado na pesquisa consiste nas poucas dificuldades encontradas nesse momento, já que os cinco entrevistados já contaram sobre a condição da adoção para os filhos. Isso pode se dar pelo fato de que essas pessoas já passaram pelo acompanhamento do estágio de convivência no projeto de extensão da Universidade denominado Terapia Familiar com 
Famílias Adotivas. Nesse acompanhamento, receberam orientações para, desde cedo, falar a verdade, desmistificando possíveis mitos ou preconceitos referentes à adoção, mostrando cada vez mais a importância da Psicologia inserida nesse contexto da adoção, facilitando o êxito nas relações. Tal fato avalia positivamente o trabalho realizado no projeto.

Pelo que parece, as dificuldades são mais relacionadas à melhor forma de educar, de passar valores, limites do que sobre falar da adoção com o filho. Cabe salientar, contudo, que questões que envolvem educação são pertinentes tanto por parte de pais adotivos quanto de pais biológicos, é natural esta preocupação.

Em alguns momentos, esses pais se mostraram angustiados, mas não se deixaram tomar por essa emoção, conseguindo assim ficar mais tranquilos para abordar o assunto com o filho, fazendo com que houvesse liberdade para, a qualquer momento, se falar sobre o tema. Assim, a relação entre pais e filhos adotivos, quando presentes a empatia e a confiança, fica mais consolidada, pois,quando qualquer assunto pertinente ao âmbito familiar for tratado de maneira natural e embasado na verdade, as relações ficam mais transparentes e leves, mesmo que por vezes sejam carregadas de algumas dificuldades. Tal postura permitirá que essas questões sejam melhor compreendidas e elaboradas para a construção da identidade e da história de vida de todos.

A forma lúdica escolhida faz com que a criança possa melhor compreender a condição da adoção, pois já vai ficando registrada no seu psiquismo. Conforme vai amadurecendo, vai entendendo sua história pré-adotiva e atual, juntando, assim, todas as peças do seu quebra-cabeças para a construção da sua identidade. Outra questão importante nessa escolha é que a revelação vai acontecendo de forma espontânea desde a chegada da criança à família, o que é um facilitador no processo da adoção.

\section{Referências Bibliográficas}

ALVARENGA, L. Adoção e mitos familiares. In: FERES-CARNEIRO, T. Casal e família, entre a tradição e a transformação. Rio de Janeiro: Nau Editores, 1999. p.164-173.

AYRES, L. S. M. Adoção: de menor a criança, de criança a filho. $1^{\text {a }}$ reimpr. Curitiba: Juruá, 2009. 
BOCHNIA, S.F. Da adoção: Categorias, paradigmas e práticas do direito de família. Curitiba: Juruá, 2010.

BOTTINO, S.S.C.A.; NETO, C. Segredo familiar: adoção. Disponível em:<//blog.newtonpaiva.br/psicologia/wp-content/uploads/2012/08/pdf-e2-02.pdf > Acesso em: 15 ago de 2012.

BRASIL. Constituição da República Federativa do Brasil. 1988.

. Lei 12010, de 3 de agosto de 2009. Dispõe sobre adoção; altera as Leis 8069/90 e $8560 / 92$ e dá outras providências.

. Lei 8069 de 13 de julho de 1990 - Estatuto da Criança e do Adolescente.

CHIZZOTTI, A. Pesquisa em ciências humanas e sociais. São Paulo: Cortez, 2001.

COHEN, N.; COYNE, J.; DUVALL. Parent's sense of entitlement in adotive and nonadoptive e families. Family Process. V.35, 1996.

COSTA, A. R. N. FERREIRA, R. C. M. Tornar-se pai e mãe em um processo de adoção tardia. Psicol. Reflex. Crit. vol.20 no.3 Porto Alegre 2007. Disponível em:

<http://www.scielo.br/scielo.php?script=sci_arttext\&pid=S010279722007000300010\&lang =pt>. Acesso em: 15 ago 2012.

COSTA, T. M. M. L. Adoção por pares homoafetivos: uma abordagem jurídica e psicológica. Revista Eletrônica de Direito Dr. Romeu Vianna, 1, Nov/2004. Disponível em: <http://www.viannajr.edu.br/revista/dir/doc/art_10005.pdf>. Acesso em: 22 set 2010.

DELL' ANTONIO, A. Algumas reflexes sobre a adoção inter-racial. In: FREIRE, F. Abandono e adoção. Contribuições para uma cultura da adoção III. Curitiba: Terra dos Homens, 2001, p.129-134.

DOLTO, F. Quando surge a criança. Campinas: Papirus, 2004.

ELDRIDGE, S. Vinte coisas que os filhos adotivos gostariam que seus pais adotivos soubessem. São Paulo: Globo, 2004.

FARIAS, M. O.; MAIA, A. C. B. Adoção por homossexuais: a família homoparental sob o olhar da psicologia jurídica. Curitiba: Juruá, 2009.

FREIRE, F. Abandono e adoção. Contribuições para uma cultura da adoção III. Curitiba: Terra dos Homens, 2001. 
GUEIROS, D. A adoção consentida: do desenraizamento social da família à prática de adoção aberta. São Paulo: Cortez, 2007.

HARTMAN, A. Os segredos na adoção. In: IMBER-BLACK,E. Os segredos na família e na terapia familiar. Porto Alegre: Artes Médicas.

HOYER, C. Os riscos na constituição psíquica, in I Congresso Internacional de Psicopatologia Fundamental e VIII Congresso Brasileiro de Psicopatologia Fundamental. Belém, 2006. Disponível em:

<http://www.fundamentalpsychopathology.org/anais2006/4.59·3.2.htm>. Acesso em: 3 mai 2008.

JULIEN, P. Abandonarás teu pai e tua mãe. Tradução Procópio Abreu. Rio de Janeiro: Companhia de Freud, 2000.

KAPLAN, H. I., SADOCK, B. J., GREBB, J. A. Compêndio de Psiquiatria: ciências do comportamento e psiquiatria clínica. 7.ed. Porto Alegre: Artmed, 2003.

LADVOCAT, C. Mitos e segredos sobre a origem da criança na família adotiva. Rio de Janeiro: Booklink, 2002.

. Famílias com filhos adotivos. In: OSÓRIO, L.C.; VALLE, M.E.P. Manual de terapia familiar. Porto Alegre: Artmed, 2009. p.286-311.

LIPP, Laura Kolberg; MELLO, Ana Beatriz Guerra; RIBEIRO, Marianne M. Stolzmann Mendes. O patinho feio no imaginário parental. Ágora, Rio de Janeiro. v.14 n. 2, July/Dec. 2011. Disponível em:

<http://www.scielo.br/scielo.php?script=sci_arttext\&pid=S0104026X2010000100015\&langpt >Acesso em: 15 ago 2012.

LEVINZON, G. K. Adoção. São Paulo: Casa do Psicólogo, 2004.

MARASCHIN, C. Pesquisar e intervir. Psicologia e Sociedade, Porto Alegre, v. 16 n 1, 2004. (Edição Especial)

PICOLIN, R. G. A adoção e seus aspectos. Disponível em:

<http://www.jurisway.org.br/v2/dhall.asp?id_dh=128> Acesso em: 30 ago 2012.

ROSAS, Rafaela. Filho Adotivo. Quando contar a verdade? Disponível em: <http://guiadobebe.uol.com.br/filho-adotivo-quando-contar-a-verdade> Acesso em: 30 ago 2012.

SALZER, L. Adoption - Surviving infertility. New York: Harper, 1991. 
SANCHES, R. M. A função da verdade. In: Psicanálise e educação: questões do cotidiano. São Paulo: Escuta, 2002.

SCHETINNI, F. Luiz. Origem, revelação e aspectos educativos na adoção. Jan, 2013. Disponível em: <http://www.interjornal.com.br/noticia.kmf?canal=279\&cod=19963926> Acesso em: 10 abr 2013

SHETTINNI, L. Adoção, origem, segredo, revelação. Recife: Edições Bagaço, 1999.

SCHREINER, G. Vamos Falar-nos de Adoção (A revelação). Apresentado em reunião de pais do grupo NEPPAJ - Jundiaí/SP - 2000. Disponível em:

<http://cecif.org.br/tt_revelacao.htm.> Acesso em 20 janeiro de 2007.

SILVA, C. L. R. de. O que é adoção. Nov 2009. Disponível em:

<http://psicologiaeadocao.blogspot.com.br/2009/11/o-que-e-adocao.html> Acesso em: 30 ago 2012.

. Falando sobre adoção com o filho. Nov 2009. Disponível em: <http://psicologiaeadocao.blogspot.com.br/2009/11/falando-sobre-adocao-com-ofilho.html> Acesso em: 30 ago 2012a.

. A criança e a importância da família. Nov 2009. Disponível em: <http://psicologiaeadocao.blogspot.com.br/2009/11/crianca-e-importancia-dafamilia.html> Acesso em: 30 ago 2012b.

. Biológico X Adotivo: Tem diferença? Ago 2012. Disponível em: <http://psicologiaeadocao.blogspot.com.br/search?updated-min=2012-01-01To0:00:0002:00\&updated-max=2013-01-01To0:00:00-02:00\&max-results=50> Acesso em: 30 ago 2012.

. Respeitando a imagem dos pais de origem. Disponível em:

<http://psicologiaeadocao.blogspot.com.br/2009/11/respeitando-imagem-dos-pais-de origem.html> Acesso em: 10 abr $2013 a$

. Gestação da alma. Disponível em:

<http://psicologiaeadocao.blogspot.com.br/2009/11/gestacao-da-alma.html> Acesso em: 10 abr 2013

. Segredo na adoção. Disponível em:

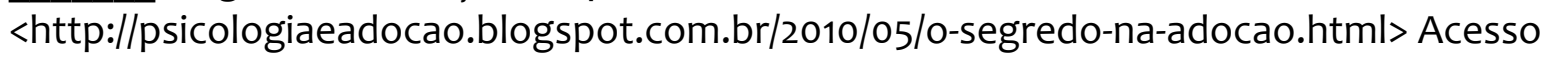
em: 10 abr $2013 \mathrm{C}$ 
. A verdade e o princípio da adoção. Disponível em:

$\overline{<\mathrm{http} / / / p s i c o l o g i a e a d o c a o . b l o g s p o t . c o m . b r / 2012 / 12 / a-v e r d a d e-e-o-p r i n c i p i o-d a-~}$ adocao.html> Acesso em: 10 abr 2013d

SILVA, F. R. C. A criança como sujeito no processo de adoção. Paidéia, Ribeirão Preto, v. 19, n. 42, Abr. 2009. Disponível em:

<http://www.scielo.br/scielo.php?script=sci_arttext\&pid=S0103863X2009000100016\&lng= en\&nrm=iso >. Acesso em: 15 ago 2012.

SOUZA, H. P. Adoção é doação. 9. Tir. Curitiba: Juruá, 2009.

SOUZA, R. P.; MIRANDA, V. R. Adoção: questões histórico-sociais, psicológicas e jurídicas. In: CARVALHO,M.C.N. \& MIRANDA, V.R. (Org.). Psicologia jurídica: temas de aplicação. 4.reimp. Curitiba: Juruá, 2011. p.79-92.

TRAVASSOS, Fernanda. Quando falar sobre a adoção? Disponível em: <http://guiadobebe.uol.com.br/quando-falar-sobre-a-adocao> Acesso em: 30 ago 2012.

VEIGA, R. C. A. Período de adaptação de acordo com a idade do adotando. Disponível em: <http://www.psicologiadaadocao.com.br/pagina.php?id_noticia=8> Acesso em: 10 jul 2012.

VIDELA, M. A procura das origens. In: FREIRE, F. Abandono e adoção. Contribuições para uma cultura da adoção III. Curitiba: Terra dos Homens, 2001. p. 165-170.

VILLA, F. O desejo e a necessidade. In: FREIRE, F. Abandono e adoção. Contribuições para uma cultura da adoção III. Curitiba: Terra dos Homens, 2001. p.33-36.

WEBER, D. N. L. Aspectos psicológicos da adoção. 2. ed., 7ºreimpr.Curitiba: Juruá, 2010. 
Recebido em: 20/09/2013 Aprovado em: 31/10/2013

Universidade do Estado de Santa Catarina - UDESC Centro de Ciências Humanas e da Educação - FAED

Revista PerCursos

Volume 14 - Número 27 - Ano 2013 revistapercursos@gmail.com 